\title{
The 1987 North West Division trainees' day
}

\author{
C. F. Sullivan and R. E. Polley, Collegiate Trainees' Committee representatives, NW \\ Division
}

The 1987 North West Division trainees' day took place at Winwick Hospital on 2 September 1987. The meeting was attended by 65 trainees and clinical tutors from the Division.

The meeting was opened by Dr Don Johnson (Chairman, NW Division) who chaired the morning session. The first speaker, Dr Digby Tantam (Senior Lecturer, University Department of Psychiatry, Manchester), gave an informative talk on the alternatives to psychiatric hospitalisation. After looking at the historical assumptions that influence planning, he pointed out that these can easily become prejudices which are embraced by the unwary. He highlighted the methodological problems in various studies purporting to answer the question of whether hospitalisation can be avoided altogether and emphasised the need for evaluation of routine services. The talk ended with a number of recommendations; perhaps the strongest message to trainees being that better kinds of hospital residence are preferable to avoiding hospitalisation at all costs and that all services should be subject to audit. This led to discussion about how appropriate the auditing role is to clinical practice and whether or not various community provisions actually provide alternatives to hospitalisation.

Dr Kay Callender (Consultant Psychiatrist, Cheadle Royal Hospital) spoke next, with a thoughtprovoking talk on the problems faced by isolated senior trainees. She reviewed the factors, both geographical and individual, which may lead to isolation and described her own experience as an isolated senior registrar in forensic psychiatry. She pointed out that comparisons with predecessors may be upsetting and the effects of isolation can be to exaggerate this out of all proportion. Recommendations to reduce isolation included contact with one's predecessor and the provision of experienced psychiatric tutors. The discussion which followed showed that many trainees identified with the 'syndrome' described and that it may be widespread amongst junior trainees in relatively isolated posts as well as amongst senior trainees. However, some of the more positive aspects were also emphasised with suggestions that isolation at a training level may have some benefits in preparing one for the relative isolation experienced on appointment as a consultant.
The morning session was closed by Mr Mike Rigby (Regional Service Development Adviser, Mersey Regional Health Authority) who gave a stimulating and provocative talk on the way in which ideas are integrated into the planning of services and how the progression of these ideas may be encouraged or frustrated. He made a convincing case for the necessity of some bureaucracy and gave a lucid description of the intricacies of the NHS planning system. He detailed the current priorities of Mersey Regional Health Authority and made a number of suggestions as to how clinicians can introduce ideas into the planning system. This provoked a discussion on how the philosophy of development is determined and how much provision for consultation exists in reality. In reply $\mathrm{Mr}$ Rigby emphasised that costed proposals should be put forward; perhaps a radical suggestion for the audience!

After lunch two workshops were formed; one concerned with the MRCPsych examination led by $\mathrm{Dr}$ Madeline Osborn (Consultant Psychiatrist, Manchester Royal Infirmary) and the other on appointment interview techniques led by Dr Claire Sillince (Consultant Psychiatrist, Park Day Hospital).

The first workshop concentrated on how to present one's findings to the examiners in the clinical section of the Membership examination. One of us brought a video of an 'unseen' clinical interview and was 'examined' on his findings by Dr Osborn. The workshop participants discussed the balance to be struck between being tentative and categorical, how to deal with remote diagnostic possibilities, what else to say to the examiner who says 'what else' and the best demeanour for the examinee (relaxed, self confident and maintaining good eye contact - adrenaline levels permitting!)

In the second group, trainees underwent mock interviews given by their peers based on rapidly completed application forms. The experience of interviewing was a novel one for most participants and led to an appreciation of some of the difficulties experienced by those on the other side of the table. The workshop ended with a discussion of how best to complete application forms and write a curriculum vitae.

The afternoon ended with a report by Dr Richard Polley (CTC representative NW Division) on the 
structure and function of the CTC and its recent activities. During the meeting, literature about the College, the new examination format and reading lists was available. The pamphlets about the exam rapidly disappeared and it was apparent from the final discussion that an issue of major concern for many trainees present was the uncharted territories of the new exam.

\section{Acknowledgement}

Our thanks are extended to the speakers and workshop leaders who helped to ensure the success of the day.

\section{Obituary}

Editor: Henry R. Rollin

\begin{abstract}
Alexander Shapiro, CBE, formerly Consultant Psychiatrist and Medical Superintendent, Harperbury Hospital, Hertfordshire, Consultant in Mental Handicap, Middlesex and Royal Free Hospitals, London, Senior Lecturer, University of London.
\end{abstract}

Dr Alexander Shapiro, a Foundation Fellow of the College, died on 1 April 1988,

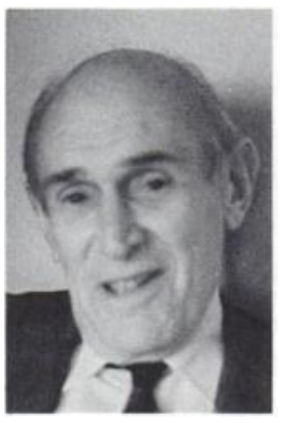
aged 76. He was a gifted, compassionate doctor, a courteous man of great scholarship and charm, a charismatic teacher, an articulate advocate and an amusing raconteur with an infectious zest for life.

Born in the Ukraine in 1911, he fled with his family from the Russian Revolution in 1919. After some time in Turkey and Paris the family settled in London in 1923. Already familiar with several languages, he quickly added English to his repertoire, thus beginning a lifelong fascination with linguistics. Even in the last three months of his life, facing with characteristic courage the inevitable approach of death, he was greatly concerned with mastering the intricacies of Japanese, his most recently acquired language.

After qualifying from University College Hospital, London, in 1935, he embarked on a career in psychiatry, choosing mental handicap as his specialty. He trained also as a psychoanalyst. He obtained the DPM in 1947 and MD London in 1949.
Apart from war service in the Mediterranean theatre with the RAFVR he spent most of his professional life at Harperbury Hospital, where he was appointed Consultant Psychiatrist in 1948, and Medical Superintendent in 1961. Under his progressive and enthusiastic leadership the hospital achieved an international reputation for high standards of service and innovative developments, noteworthy amongst which was the establishment of the Kennedy Galton Genetics Laboratory to initiate research into the causation and prevention of mental handicap.

A firm believer in the corporate strength of a professional body, Alexander Shapiro was an eager participant in the affairs of the College. A past Secretary and Chairman of the Mental Deficiency Section of the Royal Medico-Psychological Association, he was from 1951 to 1972 a Member of Council of the RMPA, serving at one time or another on all the Standing Committees. During the preparation of the 1959 Mental Health Act he was Secretary of a Joint Committee of the Medico-Psychological Association preparing evidence for the Royal Commission on Law concerning Mental Deficiency. A member of the Court of Electors and a Sub-Dean from 1972-77, his distinguished services to the Royal College of Psychiatrists were recognised by election to the Honorary Fellowship in 1981.

A national and international academic authority of high repute, he was at one time President of several learned bodies including the Section of Psychiatry of the Royal Society of Medicine, the British Society for the Study of Mental Subnormality, and the 